\title{
Methylenetetrahydrofolate Reductase Polymorphism, Plasma Folate, Homocysteine, and Risk of Myocardial Infarction in US Physicians
}

1. Jing $\mathrm{Ma}, \mathrm{MD}, \mathrm{PhD}$;

2. Meir J. Stampfer, MD, DrPH;

3. Charles H. Hennekens, MD, DrPH;

4. Phyllis Frosst, MSc;

5. Jacob Selhub, PhD;

6. Jonathan Horsford, BSc;

7. M. Rene Malinow, MD;

8. Walter C. Willett, MD, DrPH;

9. Rima Rozen, $\mathrm{PhD}$

\pm Author Affiliations

1. the Division of Preventive Medicine (C.H.H.) and Channing Laboratory (J.M., M.J.S., W.C.W.), Departments of Medicine and Ambulatory Care and Prevention (C.H.H.), Brigham and Women's Hospital and Harvard Medical School, the Departments of Epidemiology (M.J.S., C.H.H.) and Nutrition (M.J.S., W.C.W.), Harvard School of Public Health, and the Jean Mayer USDA Human Nutrition Center on Aging at Tufts University (J.S.), Boston, Mass; the Oregon Regional Primate Research Center (M.R.M.), Beaverton, Ore; and the Departments of Human Genetics, Pediatrics, and Biology, McGill University-Montreal Children's Hospital Research Institute (P.F., J.H., R.R.), Montreal, Canada.

Next Section

\begin{abstract}
Background Hyperhomocysteinemia appears to be an independent risk factor for coronary disease. Elevated levels of plasma total homocysteine (tHCY) can result from genetic or nutrientrelated disturbances in the transsulfuration or remethylation pathways for homocysteine metabolism. The enzyme 5,10-methylenetetrahydrofolate reductase (MTHFR) catalyzes the reduction of 5,10-methylenetetrahydrofolate to 5-methyltetrahydrofolate, the predominant circulatory form of folate, which serves as a methyl donor for remethylation of homocysteine to methionine. A common mutation in MTHFR recently has been identified.
\end{abstract}

Methods and Results We assessed the polymorphism in MTHFR, plasma tHCY, and folate using baseline blood levels among 293 Physicians' Health Study participants who developed myocardial infarction (MI) during up to 8 years of follow-up and 290 control subjects. The 
frequency of the three genotypes was (-/-) (homozygous normal), 47\%; (+/-) (heterozygous), $41 \%$; and $(+/+)$ (homozygous mutant), 12\%, with a similar distribution among both MI case patients and control subjects. Compared with those with genotype $(-/-)$, the relative risk (RR) of MI among those with (+/-) was $1.1(95 \%$ CI, 0.8 to 1.5$)$, and it was $0.8(0.5$ to 1.4$)$ for the $(+/+)$ genotype; none of these RRs were statistically significant. However, those with genotype $(+/+)$ had an increased mean tHCY level (mean \pm SEM, $12.6 \pm 0.5 \mathrm{nmol} / \mathrm{mL})$, compared with those with genotype $(-/-)(10.6 \pm 0.3)(P<.01)$. This difference was most marked among men with low folate levels (the lowest quartile distribution of the control subjects): those with genotype $(+/+)$ had tHCY levels of $16.0 \pm 1.1 \mathrm{nmol} / \mathrm{mL}$, compared with $12.3 \pm 0.6 \mathrm{nmol} / \mathrm{mL}(P<.001)$ for genotype $(-/-)$.

Conclusions In this population, MTHFR polymorphism was associated with higher homocysteine levels but not with risk of MI. A gene-environment interaction might increase the risk by elevating tHCY, especially when folate intake is low.

Key Words:

- folate

- homocysteine

- myocardial infarction

- genetics

- $\quad$ epidemiology

Numerous studies have shown that moderately elevated blood levels of tHCY increase the risk of cardiovascular disease,,$\underline{2} \underline{3} \underline{4} \underline{5} \underline{6} \underline{7} \underline{9} \underline{10}$ but the causes of high tHCY are only partly understood. $\underline{11}$ Elevated levels of plasma tHCY can result from genetic defects or nutrient deficiencies. $\underline{12} \underline{13} \underline{14} \underline{15}$ $\underline{16} \underline{17} \underline{18}$ Severe but rare enzymatic defects at various points in the homocysteine transsulfuration and remethylation pathways can cause dramatic elevations and lead to life-threatening vascular disease at a young age. ${ }^{16}$ The more common moderate elevation of tHCY may result from dietary deficiencies (especially folate), $\stackrel{12}{13} \underline{14}$ less severe genetic alterations in enzymes important for the metabolism of methionine/homocysteine, $\frac{15}{16}$ or perhaps a combination of the two. MTHFR catalyzes the reduction of 5,10-methylenetetrahydrofolate to 5-methyltetrahydro-folate, the predominant circulatory form of folate and methyl donor for the remethylation of homocysteine to methionine. Kang et al ${ }^{19} \underline{20} \underline{21}$ identified a thermolabile form of MTHFR that is associated with elevated tHCY levels and increased risk and severity of coronary heart disease. Recently, we isolated the cDNA for MTHFR and identified a common missense mutation, an alanine-to-valine substitution. ${ }^{22}$ Individuals heterozygous or homozygous for this mutation have reduced enzyme

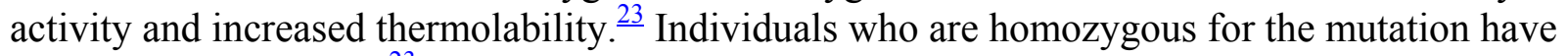
elevated plasma tHCY. ${ }^{23}$

Moderate elevations of tHCY levels caused by suboptimal intake of folate can be corrected by folic acid supplements in individuals with premature vascular disease and thermolabile MTHFR. $\underline{19} \underline{24} \underline{25} \underline{26}$ It has been hypothesized that the region in MTHFR relating to the common mutation is involved in folate binding and that the enzyme may be stabilized in the presence of folate. ${ }^{23}$ Therefore, the combination of the genetic defect and inadequate folate intake may cause elevated tHCY and increase the risk of coronary disease. 
Most clinical and epidemiological studies have focused on either the genetic variants or the nutritional factors in determining plasma tHCY levels. No studies have specifically investigated the association of the newly identified MTHFR gene polymorphism with the risk of MI and the combined influences of the gene mutation and plasma folate status. We have previously shown, in a prospective analysis, that plasma tHCY was an independent risk factor for MI among participants in the Physicians' Health Study ${ }^{3}$ in the first 5 years but was weaker and not significantly predictive of risk for cases that occurred later. ${ }^{10}$ We reported that a low plasma folate level was associated with a moderate increase in risk of MI, although this association was not statistically significant..$^{10} \mathrm{We}$ now present results from this ongoing prospective study testing two hypotheses: first, that the mutation in MTHFR might increase the risk of MI by elevating blood levels of tHCY and second, that high folate intake might compensate for this genetic defect by lowering plasma tHCY levels in individuals with the mutation.

Previous SectionNext Section

\section{Methods}

\section{Population and Specimen Collection}

The Physicians' Health Study was a randomized, double-blind, placebo-controlled trial of aspirin and $\beta$-carotene among 22071 US male physicians 40 to 84 years old. ${ }^{27}$ Men were excluded if they had a history of MI, stroke, or transient ischemic attack; cancer (except nonmelanoma skin cancer); current renal or liver disease; peptic ulcer or gout; or current use of a vitamin A or $\beta$ carotene supplement.

Before randomization, participants were sent kits for blood sampling and were instructed to have their blood drawn into EDTA vacuum tubes, to centrifuge them, and to return the plasma (as well as the whole blood) in polypropylene cryopreservation vials by prepaid overnight courier. The kit included a cold pack to keep the specimens cool (but not frozen) until receipt at Channing Laboratory the following morning, when they were promptly divided into aliquots and stored at $-80^{\circ} \mathrm{C}$. During storage, no specimen thawed or warmed substantially. Specimens were received from 14916 (68\%) of the randomized physicians, $>70 \%$ of these between September and November of 1982.

At the time of the blood sampling, participating physicians also reported their baseline cardiovascular risk factors: these included age, smoking status (past, present, or never), height, weight, systolic and diastolic blood pressures, history of angina, hypertension, and diabetes, multivitamin use (past, present, or never), parental history of MI before 60 years of age, and frequency of alcohol intake.

\section{Ascertainment and Confirmation of End Points}

Cases of nonfatal MI were reported on questionnaires mailed to participants every 6 months. Persistent nonresponders were telephoned. Deaths were usually reported by the families or postal authorities. We included case patients diagnosed up to 8 years after the blood sampling. Followup for nonfatal events was $99.7 \%$ complete and for fatal outcomes, $100 \%$ complete. Medical 
records were reviewed by the End Points Committee, who were blinded to treatment assignment. All cases of MI included in this analysis met the World Health Organization criteria, ${ }^{28}$ which require symptoms plus either enzyme elevations or diagnostic ECG changes. For fatal cases, diagnoses were based on either autopsy or confirmation via records that death was due to coronary heart disease (International Classification of Diseases, codes 411 through 414). Silent infarcts discovered on routine examination were not included because they could not be assigned an accurate date. Sudden deaths in individuals with no history of coronary disease were not included because coronary disease could not be confirmed as the cause of death.

\section{Selection of Case Patients and Control Subjects}

Each case patient was matched to one control subject who was free of MI at the time of diagnosis of MI in the case patient. Control subjects were randomly selected from participants who met the matching criteria of age ( \pm 1 year), smoking habit (current, past, or never smoker), and time from randomization in 6-month intervals. Aliquots from case patients and control subjects were paired, with the positions varied at random within the pairs. The pairs were handled together and identically throughout processing and analysis.

\section{Laboratory Analyses}

DNA was extracted by a commercially available process based on the adsorption of DNA to a silica membrane after lysis with a proprietary agent (Diagen) and proteinase $\mathrm{K}$ in the presence of a high salt concentration and 33\% isopropanol. The extracted DNA samples were shipped on dry ice to the Montreal Children's Hospital Research Institute for MTHFR genotype analysis in Dr Rozen's laboratory, where the investigators and laboratory personnel were blinded to each subject's status as a case patient or control subject. The presence of the mutation was determined by polymerase chain reaction of genomic DNA, followed by HinfI restriction digestion, as previously described. $\underline{23}$

Plasma tHCY level was assayed by Dr M. Rene Malinow's laboratory by high-performance liquid chromatography and electrochemical detection based on the method of Smolin and Schneider, ${ }^{29}$ modified as described..$\underline{31} \stackrel{31}{ }$ Plasma levels of folate were measured microbiologically with a 96-well plate and manganese supplementation, as described by Tamura et al, $\frac{32}{}$ in the laboratory of Dr Jacob Selhub. This method measures all biologically active forms of folate. Levels of total and HDL cholesterol were measured in the laboratory of Dr Frank Sacks. ${ }^{33}$

Blind paired quality-control samples (16 pairs for folate and 29 pairs for tHCY) were interspersed at random among the specimens. The quality-control samples were aliquots of a large, well-mixed plasma pool from healthy volunteers and were treated identically to the samples collected from the participants. The mean within-pair coefficients of variation in these paired quality-control specimens were $10 \%$ for folate and $3.9 \%$ for $\mathrm{tHCY}$.

It is unlikely that the storage period significantly altered the concentrations of tHCY and folate. Israelsson et $\mathrm{al}^{34}$ found that $\mathrm{tHCY}$ concentration in stored plasma kept at $-20^{\circ} \mathrm{C}$ remained stable for up to 10 years and was strongly correlated with that in fresh plasma. The levels of folate and tHCY we found were generally similar to those from fresh plasma. More importantly, the 
samples from case patients and control subjects were stored for the same duration and were handled together and identically throughout processing. Because of the prospective design, it is unlikely that any deterioration would systematically differ by case status. Any random changes would tend to blur the differences, leading to an underestimate of the real effect.

\section{Statistical Analysis}

The MTHFR genotype was ascertained among 293 case patients and 290 control subjects who provided an adequate sample of whole blood at baseline and also had plasma folate and tHCY measured. We identified the MTHFR genotype in 245 case patients and 224 control subjects in the first 6 years of follow-up. To examine the interaction between the gene mutation and folate levels, 48 case patients and 66 control subjects from the later follow-up were oversampled from the lowest and highest quartiles of the overall control distribution of plasma folate levels. This equal oversampling from the extremes of the folate distribution was done before identification of the genotype and therefore does not introduce a bias. However, it does add to the efficiency of the analysis by providing greater statistical power to detect differences contrasting the extremes of folate status.

As in our previous report from this study population, ${ }^{3}$ tHCY concentrations $>15.8 \mathrm{nmol} / \mathrm{mL}$ were defined as abnormally high values and those below as normal. To estimate RRs, the odds ratios for case patients relative to control subjects were calculated with the homozygous normal genotype (-l-) of MTHFR used as the reference group. To estimate the joint effect of gene mutation and plasma folate status on the risk of MI, folate levels above the 75th percentile of the overall control distribution were defined as high values, and those below the 25th percentile were defined as low. Six groups based on the cross-classification by the two folate groups and the three MTHFR genotypes were formed. The odds ratios were then calculated with each group compared with the reference group of men with homozygous normal gene (-l-) and high folate level. Unconditional logistic regression analyses were used to adjust simultaneously for both the matching factors and other known coronary risk factors.

To examine the effects of genetic and nongenetic factors on folate and tHCY levels, an ANCOVA was used to calculate age-adjusted means of folate and tHCY according to genotype $(-/-,+/-$, and $+/+)$, cigarette smoking, and multivitamin use (both as never, past, or current users). The adjusted means of tHCY were also calculated according to folate level (quartile distribution of control subjects). The change in tHCY levels associated with the genetic and nongenetic factors was estimated by linear regression modeling. Stratified analyses were done according to folate status (quartiles) and age ( $<60$ years and $\geq 60$ years). Because matched analyses yielded results virtually identical to unmatched, only the latter are presented. To improve the normality of the variables, the analyses using natural log-transformed folate and tHCY in the ANCOVA and regression analyses were repeated, and similar results were found for tHCY. The mean levels of tHCY from the ANCOVA analysis are presented, as are the untransformed results for the regression analysis. All probability values are two-tailed, and statistical significance is taken at the $P=.05$ level. Statistical analysis was done with the SAS package. $\frac{35}{}$

Previous SectionNext Section 


\section{Results}

MI case patients had higher Quetelet's index, total cholesterol, and ratio of total to HDL cholesterol and a higher prevalence of diabetes, angina, hypertension, and family history of MI before age 60 years. ${ }^{3}$ Case patients had higher mean tHCY $(11.3 \pm 4.3 \mathrm{nmol} / \mathrm{mL})$ than control subjects $(10.6 \pm 4.1 \mathrm{nmol} / \mathrm{mL}, P=.06)$. The prevalence of moderate hyperhomocysteinemia (values $>15.8$ ) was $12 \%$ in case patients and $6 \%$ in control subjects $(P=.004)$. Geometric mean folate levels in case patients $(3.3 \mathrm{ng} / \mathrm{mL})$ were not significantly lower than those of control subjects (3.7 ng/mL), $P=.19$.

The overall frequencies of the three MTHFR genotypes were similar among case patients and control subjects (Table $1 \underline{\Downarrow})$. However, high frequencies of the type $(+/+)$ were observed among men with diabetes (21\%), angina (24\%), hypertension (17\%), and family history of MI (16\%) compared with men without these conditions (11\% to $12 \%)$. Higher frequencies were also seen among men with low folate (15\% versus $9 \%$, high folate versus low) or high tHCY (21\% versus $12 \%$, high versus normal) levels.

View this table:

- $\quad \underline{\text { In this window }}$

- $\underline{\text { In a new window }}$

Table 1.

Frequency of the MTHFR Genotypes and RR of Future MI Among US Physicians

\section{MTHFR Genotype, Folate, and tHCY Levels}

Multivitamin use and cigarette smoking were significant determinants of blood folate level (Table $2 \underline{\Downarrow}$ ). In addition to these nongenetic influences, the homozygous mutation in MTHFR was also associated with a lower level of plasma folate (Table $2 \underline{\Downarrow}$ ). Among those with folate levels in the lowest quartile, those with genotype $(+/+)$ had a geometric mean folate level of $0.66 \mathrm{ng} / \mathrm{mL}$ $(P<.05)$, significantly lower than those with $(+/-), 1.10 \mathrm{ng} / \mathrm{mL}$, and those with $(-/-), 1.29$ $\mathrm{ng} / \mathrm{mL}$. In contrast, within the second to fourth quartiles of folate levels, folate levels did not vary by genotype.

View this table:

- $\quad \underline{\text { In this window }}$

- $\underline{\text { In a new window }}$

Table 2 .

Age-Adjusted Geometric Mean Folate Level and Mean $( \pm$ SEM) Plasma tHCY Level According to MTHFR Genotype, Smoking Status, and Multivitamin Use 
Consistent with the above observations, the age-adjusted tHCY levels in (+/+) genotype individuals were significantly higher than in $(-/-)$ individuals (Table $2 \Uparrow$ ). Similar results were observed among case patients and control subjects. tHCY levels also varied by smoking status and folate levels. In addition, current multivitamin users had lower tHCY levels, reflecting a higher intake of folate and possibly of vitamin $\mathrm{B}_{6}$.

We further examined the effect of folate on the relation between genotype and tHCY level. Table $3 \underline{\underline{ }}$ shows the mean tHCY level according to the genotype and plasma folate level (based on the quartile distribution of control subjects). A significantly elevated mean tHCY level among $(+/+)$ individuals was observed only in the low-folate group; in the high-folate group, tHCY levels were similar regardless of MTHFR genotype. We observed similar results when we dichotomized the population by multivitamin supplement use. Among nonusers, men with the $(+/+)$ genotype had significantly elevated tHCY compared with $(-/-)$, but no material differences by genotype were found among multivitamin users. Conversely, the prevalence of the $(+/+)$ genotype within different levels of tHCY also varied by plasma folate level (Figure $\underline{\Downarrow}$ ). Among the 28 men with low plasma folate who were homozygous for the mutant gene $(+/+), 9$ were in the higher-tHCY groups ( $\geq 14 \mathrm{nmol} / \mathrm{mL}$ ). In contrast, among men with high plasma folate, all 16 individuals with $(+/+)$ genotype had tHCY levels $<12 \mathrm{nmol} / \mathrm{mL}$.

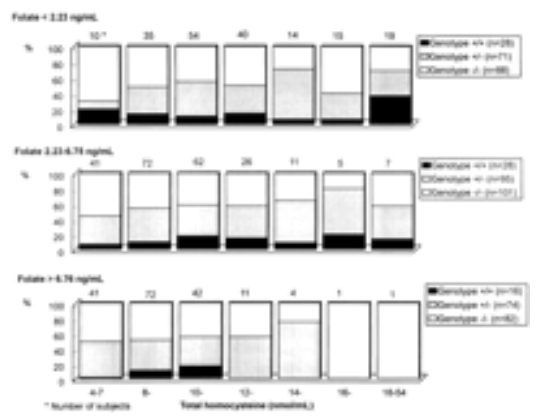

View larger version:

- In this page

- $\underline{\text { In a new window }}$

- Download as PowerPoint Slide

Figure 1.

Frequency distribution of the MTHFR genotypes (case patients and control subjects combined) by plasma tHCY level, stratified by plasma folate in three separate panels.

View this table:

- In this window

- $\underline{\text { In a new window }}$

Table 3. 
Age-Adjusted Mean ( $($ SEM) Plasma tHCY Level (nmol/mL) According to MTHFR Genotype and Folate Levels (Quartiles 1, 2+3, and 4)

Multiple linear regression was used to estimate the independent effects of the gene

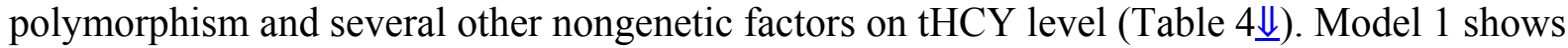
that the MTHFR gene mutation was independently associated with tHCY level regardless of case/control status, age, and cigarette smoking status. Plasma folate level is influenced by diet as well as the gene mutation, and high tHCY levels can often be treated with folate supplements. Therefore, we included multivitamin use and folate level in model 2 to determine whether plasma folate, as an intermediary in the biological pathway, is fully responsible for the above effects on tHCY. As shown in model 2, the associations of tHCY level with MTHFR genotype mutation and smoking were weakened but still significant. This result suggests that plasma folate may reflect both genetic and nongenetic influences on tHCY. Furthermore, it remained the strongest determinant of blood tHCY level in the model.

View this table:

- $\quad \underline{\text { In this window }}$

- $\underline{\text { In a new window }}$

Table 4.

$\beta$-Coefficients of Plasma tHCY (nmol/mL) From Multiple Linear Regression Analysis

The associations of tHCY levels with MTHFR gene mutation, age, smoking, multivitamin use, and plasma folate were then examined according to two age groups, those $<60$ and those $\geq 60$ years old (Table $4 \mathbb{1}$ ). Among younger men, the homozygous mutation in the MTHFR gene appears to be the major determinant of tHCY level, whereas for older men, age, current smoking, current multivitamin use, and plasma folate status were the major determinants, and the mutation was no longer significantly associated with tHCY level.

\section{MTHFR Genotype and Risk of MI}

We found no increased risk of MI according to the MTHFR genotype alone; the age- and smoking-adjusted RR and 95\% CI for type (+/-) were $1.07(0.75$ to 1.51$)$ and for type (+/+), 0.84 $(0.50$ to 1.42$)$. Since somewhat higher frequencies of $(+/+)$ were observed among men with diabetes, angina, hypertension and family history of MI, we further adjusted for these and other coronary risk factors, with or without tHCY levels, but the results did not change materially (Table 1爪). The addition of the MTHFR genotype to the model did not alter the magnitude of the positive association between abnormally high tHCY and future risk of MI.

We further examined the interaction between MTHFR mutation and plasma folate status by calculating RRs of MI according to genotype among individuals with low and high folate levels. Defining men with high folate and genotype $(-/-)$ as the reference group $(\mathrm{RR}=1.0)$, the age- and smoking-adjusted RRs in the high-folate group were $1.2(95 \% \mathrm{CI}, 0.6$ to 2.3$)$ for genotype $(+/-)$ and $1.6(0.6$ to 4.8$)$ for genotype $(+/+)$. In the low-folate group, they were 1.3 (0.7 to 2.4$)$ for 
genotype (-/-), 1.9 (1.0 to 3.6) for genotype (+/-), and $1.1(0.4$ to 2.5$)$ for genotype $(+/+)$. Because of the limited sample size in each subgroup, we combined genotypes $(+/-)$ and $(+/+)$ in an alternative analysis. Using men with high folate and homozygous normal $(-/-)$ as the reference group $(\mathrm{RR}=1.0)$, the $\mathrm{RRs}$ were as follows: for those with high folate and genotype $(+/-)$ or $(+/+), R R=1.3(0.7$ to 2.4$)$; for those with low folate and genotype $(-/-), R R=1.3(0.7$ to $2.4)$; and for those with low folate and genotype $(+/-)$ or $(+/+), R R=1.6(0.9$ to 2.9$)$. None of these interactions were significant.

Because the genotype was the major determinant of plasma tHCY in the younger men $(<60$ years old) (Table 4爪), we further stratified these analyses by age. The findings were null among older men. Among younger men, with high folate and genotype $(-/-)$ as the reference, the age- and smoking-adjusted RRs in the high-folate groups were $1.6(0.6$ to 4.6$)$ for genotype $(+/-)$ and 1.4 $(0.2$ to 8.3$)$ for genotype $(+/+)$. In the low-folate group, they were $1.6(0.6$ to 4.3$)$ for $(-/-), 3.7$ (1.3 to 10.4$)$ for $(+/-)$, and $0.7(0.2$ to 3.1$)$ for $(+/+)$. When the $(+/-)$ and $(+/+)$ genotypes were combined, for high folate the RR was $1.6(0.6$ to 4.3$)$ for genotypes $(+/-)$ and $(+/+)$. For low folate, the RR was 1.7 (0.7 to 4.5) for genotype (-/-) and 2.4 (0.9 to 6.4) for the combined genotype $(+/-)$ and $(+/+)$.

\section{Previous SectionNext Section}

\section{Discussion}

Among these middle-aged US male physicians, the heterozygous and homozygous MTHFR gene mutation is common. The frequency of the three genotypes of MTHFR among control subjects was homozygous normal (-/-), 47\%; mutation in the heterozygous state $(+/-), 40 \%$; and homozygous mutant $(+/+), 13 \%$. The allele frequency of the substitution was $33 \%$, consistent with the previous report of 114 unselected French Canadian chromosomes. $\stackrel{23}{ }$ Several studies suggest that this polymorphism may be the only mutation that accounts for thermolabile MTHFR. $\underline{36} \underline{37} \underline{38}$ In addition to the original report, $\underline{23}$ two studies of vascular disease $\underline{\underline{36}} \underline{\underline{37}}$ and one study of neural tube defects ${ }^{38}$ have shown distinct thermolability for the homozygous mutant genotype. The mean value for thermolabile MTHFR activity in heterozygotes has been intermediate between the homozygous mutant group and the homozygous normal group $\underline{23}^{\underline{36}} \underline{37}$; all the individuals without this mutation had residual enzyme activity $>30 \%$ after samples were heated. $\underline{36} \underline{37} \underline{38}$ In the original description of thermolabile MTHFR, Kang et al ${ }^{\underline{20}}$ reported a prevalence of $17 \%$ in patients with coronary artery disease and 5\% in control subjects. However, since both heterozygotes and homozygotes for the mutation have the thermolabile enzyme, it is possible that individuals with the thermolabile enzyme in the above report included both of these genotypes.

Van der Put et al ${ }^{\frac{38}{3}}$ recently reported decreased plasma folate concentrations in individuals homozygous for the mutation. We have similar findings, but the differences in folate levels among the genotypes were significant only in the lowest folate quartile group, in which the $(+/+)$ genotype was associated with approximately half the plasma folate level of the (-/ - ) genotype. Since the product of MTHFR, 5-methyltetrahydrofolate, is the major circulating form of folate, when folate intake is low, the mutation, which leads to decreased MTHFR activity, might reduce total folate pools in plasma. 
We observed a positive association between the homozygous $(+/+)$ mutation and elevated plasma

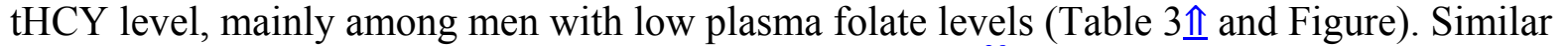
findings were observed in the NHLBI Family Heart Study. ${ }^{39}$ This association suggests that the MTHFR gene mutation may increase plasma tHCY levels when folate intake is low. These findings further support the hypothesis that folate may stabilize the MTHFR enzyme ${ }^{23}$ and are consistent with the observation that oral supplementation of folic acid normalizes hyperhomocysteinemia due to thermolabile MTHFR. ${ }^{12} \underline{19}$ Our results also indicate that when folate consumption is high, this common genetic variant has little effect on tHCY levels.

After the nongenetic factors (such as smoking, multivitamin use, and folate status) were adjusted for, we found that genotype $(+/+)$ individuals had a tHCY level $1.9 \mathrm{nmol} / \mathrm{mL}$ higher than those with the $(-/-)$ genotype. Similar elevations were observed for current smokers compared with nonsmokers. Plasma folate remained a strong predictor in the model: the tHCY level was 3.31 $\mathrm{nmol} / \mathrm{mL}$ higher among men with a folate level in the lowest quartile. As expected, the genetic influence on tHCY was more predominant among younger men, whereas among older men, nongenetic influences (such as cigarette smoking and folate intake) were stronger.

Overall, we found no direct association between the MTHFR genotype and risk of MI. However, among those with low levels of folate, we found a nonsignificantly increased risk among those with the mutation. The absence of a significant risk among those with low folate and genotype $(+/+)$ was unexpected; however, the size of this group was small and the CI was wide. A significantly higher prevalence (17\%) of the thermolabile MTHFR was reported among 212 patients with coronary artery disease, compared with $5 \%$ of the 202 control subjects. ${ }^{20}$ Thermolabile MTHFR has also been associated with the severity of coronary artery stenosis independently of other risk factors. ${ }^{21}$ Although a strong correlation has been found between the gene mutation in MTHFR and the thermolability of the enzyme, $\underline{23} \underline{36} \underline{37} \underline{38}$ ethnic differences, folate status in the population, and different study designs may contribute to the inconsistencies in these studies. Kluijtmans et al ${ }^{36}$ found a threefold-increased risk of premature cardiovascular disease among those with (+/+) genotype in 60 Dutch patients and 111 control subjects. The age of onset of disease among their case patients is much younger than our case patients. They excluded patients with known cardiovascular disease risk factors, such as hyperlipoproteinemia, hypertension, and diabetes. Furthermore, the prevalence of the homozygous mutation in the MTHFR gene among their control subjects ( $n=6$ of $111,5.4 \%)$ is much lower than ours $(13 \%)$.

Despite the clear effect of the genetic polymorphism on increasing tHCY levels, especially among those with lower folate intake, we found no association between MTHFR genotype and the risk of MI among these US physicians. However, this genetic defect is likely to affect the risk of MI indirectly through its independent influence on the tHCY level, especially among younger men or men with low folate levels. Another possibility is that overall, among these wellnourished physicians, the genetic defect might largely be compensated by folate intake. It will be of great interest to determine the impact of this polymorphism in a general population sample with lower intake of folate and among young individuals.

Our findings demonstrate genetic, nutritional, and other influences on plasma tHCY levels, which should be taken into account in the design of randomized trials of tHCY lowering. These results raise the possibility but do not confirm that individuals with homozygous mutation in the 
MTHFR gene may be able to compensate for the genetic disturbance in tHCY metabolism through increasing intake of folate.

$\underline{\text { Previous SectionNext Section }}$

\section{Selected Abbreviations and Acronyms}

MI = myocardial infarction

MTHFR $=5,10$-methylenetetrahydrofolate reductase

$\mathrm{RR} \quad=$ relative risk

tHCY = total homocysteine

Previous SectionNext Section

\section{Acknowledgments}

This study was supported by research grants CA-42182 and CA-40360 from the National Institutes of Health. The authors thank the participants of the Physicians' Health Study for their cooperation and participation. The authors are also indebted to Rachel Meyer, Michele Lachance, Kathie Schneider, and Stefanie Parker for their expert and unfailing assistance. We are grateful to Dr Klaus Lindpaintner, who prepared the DNA, and to Dr Andy Bostom for many useful discussions.

$\underline{\text { Previous SectionNext Section }}$

\section{Footnotes}

- Reprint requests to Dr Jing Ma, Channing Laboratory, 180 Longwood Ave, Boston, MA 02115. E-mail hpjma@gauss.med.harvard.edu.

- $\quad$ Received March 21, 1996.

- Revision received May 31, 1996.

- Accepted June 13, 1996.

- Copyright (C) 1996 by American Heart Association

$\underline{\text { Previous Section }}$

\section{References}

1. $\Perp$ 
McCully KS. Vascular pathology of homocysteinemia: implications for the pathogenesis of arteriosclerosis. Am J Pathol. 1969;56:111-128.

$\underline{\text { Medline }}$

2. $\Perp$

Genest JJ Jr, McNamara JR, Salem DN, Wilson PWF, Schaefer EJ, Malinow MR. Plasma homocyst(e)ine levels in men with premature coronary artery disease. J Am Coll Cardiol. 1990;16:1114-1119.

\section{$\underline{\text { Abstract }}$}

3. $\Perp$

Stampfer MJ, Malinow MR, Willett WC, Newcomer L, Upson B, Ullmann D, Tishler P, Hennekens $\mathrm{CH}$. A prospective study of plasma homocyst(e)ine and risk of myocardial infarction in US physicians. JAMA. 1992;268:877-881.

CrossRefMedline

4. $\Perp$

Brattstro"m LE, Lindgren A, Israelsson B, Malinow MR, Norrving B, Upson B, Hamfelt A. Hyperhomocysteinaemia in stroke: prevalence, cause, and relationships to type of stroke and stroke risk factors. Eur J Clin Invest. 1992;22:214-221.

$\underline{\text { Medline }}$

5. $\Perp$

Brattstro"m L, Israelsson B, Norrving B, Bergqvist D, Tho"rne J, Hultberg B, Hamfelt A. Impaired homocysteine metabolism in early-onset cerebral and peripheral occlusive arterial disease: effects of pyridoxine and folic acid treatment. Atherosclerosis. 1990;81:51-60.

CrossRefMedline

6. $\Perp$

Arnesen E, Refsum H, Bønaa KH, Ueland PM, Førde OH, Nordrehaug JE. Serum total homocyst(e)ine and coronary heart disease. Int J Epidemiol. 1995;24:704-709.

\section{$\underline{\text { Abstract/FREE Full Text }}$}

7. $\Perp$ 
Selhub J, Jacques PF, Bostom AG, D'Agostino RB, Wilson PWF, Belanger AJ, O'Leary DH, Wolfe PA, Schaefer EJ, Rosenberg IH. Association between plasma homocysteine concentrations and extracranial carotid-artery stenosis. N Engl J Med. 1995;332:286291.

\section{$\underline{\text { CrossRefMedline }}$}

8. $\leftrightarrows$

Malinow MR, Nieto FJ, Szklo M, Chambless LE, Bond G. Carotid artery intimal-medial wall thickening and plasma homocyst(e)ine in asymptomatic adults: the Atherosclerosis Risk in Communities Study. Circulation. 1993;87:1107-1113.

\section{$\underline{\text { Abstract/FREE Full Text }}$}

9. $\Perp$

Boushey CJ, Beresford SAA, Omenn GS, Motulsky AG. A quantitative assessment of plasma homocysteine as a risk factor for vascular disease: probable benefits of increasing folic acid intakes. JAMA. 1995;274:1049-1057. (See Comments.)

\section{$\underline{\text { CrossRefMedline }}$}

$10 . \longleftarrow$

Chasan-Taber L, Selhub J, Rosenberg IH, Malinow MR, Terry P, Tishler PV, Willett WC, Hennekens $\mathrm{CH}$, Stampfer MJ. A prospective study of folate and vitamin B6 and risk of myocardial infarction in U.S. physicians. J Am Coll Nutr. 1996;15:136-143.

\section{$\underline{\text { Abstract }}$}

11.

Selhub J, Miller JW. The pathogenesis of homocysteinemia: interruption of the coordinate regulation by $S$-adenosylmethionine of the remethylation and transsulfuration of homocysteine. Am J Clin Nutr. 1992;55:131-138.

\section{Abstract/FREE Full Text}

12. 4

Kang S-S, Wong PWK, Norusis M. Homocysteinemia due to folate deficiency. Metabolism. 1987;36:458-462.

CrossRefMedline 
$13 . \unlhd$

Stabler SP, Marcell PD, Podell ER, Allen RH, Savage DG, Lindenbaum J. Elevation of total homocysteine in the serum of patients with cobalamin or folate deficiency detected by capillary gas chromatography-mass spectrometry. J Clin Invest. 1988;81:466-474.

14. $\underline{\uplus}$

Selhub J, Jacques PF, Wilson PWF, Rush D, Rosenberg IH. Vitamin status and intake as primary determinants of homocysteinemia in an elderly population. JAMA. 1993;270:2693-2698.

$\underline{\text { CrossRefMedline }}$

15.

Kang S-S, Zhou J, Wong PWK, Kowalisyn J, Strokosch G. Intermediate homocysteinemia: a thermolabile variant of methylenetetrahydrofolate reductase. Am J Hum Genet. 1988;43:414-421.

$\underline{\text { Medline }}$

16. $\underline{4}$

Kang S-S, Wong PWK, Bock H-GO, Horwitz A, Grix A. Intermediate hyperhomocysteinemia resulting from compound heterozygosity of methylenetetrahydrofolate reductase mutations. Am J Hum Genet. 1991;48:546-551.

$\underline{\text { Medline }}$

17. $\Perp$

Rosenblatt DS. Inherited disorders of folate transport and metabolism. In: Scriver CR, Beaudet AL, Sly WS, Valle D, eds. The Metabolic and Molecular Bases of Inherited Disease, Vol 1. 7th ed. New York, NY: McGraw-Hill; 1995:3111-3128.

$18 . \underline{4}$

Wu LL, Wu J, Hunt SC, James BC, Vincent GM, Williams RR, Hopkins PN. Plasma homocyst(e)ine as a risk factor for early familial coronary artery disease. Clin Chem. 1994;40:552-561.

$\underline{\text { Abstract/FREE Full Text }}$

19. 
Kang S-S, Wong PWK, Zhou J, Sora J, Lessick M, Ruggie N, Greevich G. Thermolabile methylenetetrahydrofolate reductase in patients with coronary artery disease.

Metabolism. 1988;37:611-613.

\section{$\underline{\text { CrossRefMedline }}$}

20. $\Perp$

Kang S-S, Wong PWK, Susmano A, Sora J, Norusis M, Ruggie N. Thermolabile methylenetetrahydrofolate reductase: an inherited risk factor for coronary artery disease. Am J Hum Genet. 1991;48:536-545.

$\underline{\text { Medline }}$

$21 . \pm$

Kang S-S, Passen EL, Ruggie N, Wong PWK, Sora H. Thermolabile defect of methylenetetrahydrofolate reductase in coronary artery disease. Circulation. 1993;88:1463-1469.

\section{$\underline{\text { Abstract/FREE Full Text }}$}

22.

Goyette P, Sumner JS, Milos R, Duncan AMV, Rosenblatt DS, Matthews DS, Matthews RG, Rozen R. Human methylenetetrahydrofolate reductase: isolation of cDNA, mapping and mutation identification. Nat Genet. 1994;195-200.

23.

Frosst P, Blom MJ, Lios R, Goyette P, Sheppard CA, Matthews RG, Boers GJH, den Heijer M, Kluitjmans LAJ, van den Heuvel LP, Rozen $R$. A candidate genetic risk factor for vascular disease: a common mutation in methylenetetrahydrofolate reductase. Nat Genet. 1995;10:111-113.

\section{$\underline{\text { CrossRefMedline }}$}

24. $\Perp$

Brattstro"m L, Israelsson B, Japsson JO, Hultberg BL. Folic acid: an innocuous means to reduce plasma homocysteine. Scand J Clin Lab Invest. 1988;48:215-221.

$\underline{\text { Medline }}$

25. $\Perp$ 
Malinow MR. Hyperhomocysteinemia: a common and easily reversible risk factor for occlusive atherosclerosis. Circulation. 1990;81:2004-2006.

\section{$\underline{\text { FREE Full Text }}$}

26.

Landgren F, Israelsson B, Lindgren A, Hultberg B, Anderson A, Brattstro"m L. Plasma homocysteine in acute myocardial infarction: homocysteine-lowering effect of folic acid. J Intern Med. 1995;237:381-388.

$\underline{\text { Medline }}$

27.

Steering Committee of the Physicians' Health Study Research Group. Final report of the aspirin component of the ongoing Physicians' Health Study. N Engl J Med. 1989;321:129-135.

$\underline{\text { Medline }}$

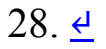

IHD Registers. Report of the Fifth Working Group. Copenhagen, Denmark: World Health Organization; 1971.

$29 . \unlhd$

Smolin LA, Schneider JA. Measurement of total plasma cysteamine using highperformance liquid chromatography with electrochemical detection. Anal Biochem. 1988;168:374-379.

$\underline{\text { CrossRefMedline }}$

30.

Malinow MR, Kang SS, Taylor LM, Wong PW, Coull B, Inahara T, Mukerjee D, Sexton $G$, Upson B. Prevalence of hyperhomocyst(e)inemia in patients with peripheral arterial occlusive disease. Circulation. 1989;79:1180-1188.

\section{$\underline{\text { Abstract/FREE Full Text }}$}

$31 . \underline{\Perp}$

Malinow MR, Sexton G, Averbuch M, Grossman M, Wilson D, Upson B. Homocyst(e)ine in daily practice: levels in coronary artery disease. Coron Artery Dis. 1990;1:215-220. 
$32 . \unlhd$

Tamura T, Freeberg LE, Cornwell PE. Inhibition by EDTA of growth of Lactobacillus casei in the folate microbiological assay and its reversal by added manganese or iron. Clin Chem. 1990;36:1993.

\section{$\underline{\text { FREE Full Text }}$}

33. $\Perp$

Stampfer MJ, Sacks FM, Salvini S, Willett WC, Hennekens CH. A prospective study of cholesterol, apolipoproteins, and the risk of myocardial infarction. $N$ Engl J Med. 1991;325:373-381.

$\underline{\text { Medline }}$

34. $\underline{4}$

Israelsson B, Brattstro“m L, Refsum H. Homocysteine in frozen plasma samples: a shortcut to establish hyperhomocysteinaemia as a risk factor for arteriosclerosis? Scand $J$ Clin Lab Invest. 1993;53:465-469.

\section{$\underline{\text { Medline }}$}

35. $\Perp$

SAS Institute, Inc. SAS/STATR User's Guide Version 6, 4th Ed, Vol 2. Cary, NC: SAS Institute Inc; 1989:846.

36.

Kluijtmans LAJ, van den Heuvel LP, Boers GHJ, Frosst P, Stevens EMB, van Oost BA, den Heijer M, Trijbels FJM, Rozen R, Blom HJ. Molecular genetic analysis in mild hyperhomocysteinemia: a common mutation in the methylenetetrahydrofolate reductase gene is a genetic risk factor for cardiovascular disease. Am J Hum Genet. 1996;58:3541.

\section{Medline}

37. $\underline{4}$

Christensen B, Frosst P, Goyette P, Selhub J, Rosenblatt DS, Genest J Jr, Rozen R. Methylenetetrahydrofolate reductase in premature CAD: correlation of enzymatic activity and thermolability with genotype and plasma homocysteine. Circulation. 1995;92(suppl I):I-103. 
38.

van der Put NM, Steegers-Theunissen PM, Frosst P, Trijbels FJM, Eskes TK, van den Heuvel LP, Mariman ECM, den Heyer M, Rozen R, Blom HJ. Mutated methylenetetrahydrofolate reductase as a risk factor for spina bifida. Lancet. 1995;346:1070-1071.

$\underline{\text { CrossRefMedline }}$

39.

Jacques PF, Bostom AG, Williams RR, Ellison RC, Eckfeldt JH, Rosenberg IH, Selhub J, Rozen $R$. Relation between folate status, a common mutation in methylenetetrahydrofolate reductase, and plasma homocysteine concentrations. Circulation. 1996;93:7-9. 